is clearly due to a series of extra systoles. The regularity of their occurrence does not speak against their extra-systolic nature, as we have seen the regular occurrence of extra systoles in Fig. 8. Similar tracings with rhythmical extra systoles have been published by Gerhardt and Lommel.10

Tracings showing the pathogenesis of the attacks were only obtained in these 2 cases, hut in other cases auscultatory evidence of the extra-systolic character of the paroxysmal attack could be obtained. It would be entirely hypothetical to try to explain the attack from a physiological standpoint. Whether disense of the vagus nerve alone or in combination with an irritation of the accelerans may cause such an attack is difficult to determine in the absence of physiological experiments. Further investigations may clear up the question, in which conditions the point of origin for the stimulus changes from the venous sinus to the atrioventricular bundle.

The argument presented in this paper, however, emphasizes the pathological importance of the atrioventricular conducting system. It is interesting to note that paroxysmal and permanent bradycardia, as well as paroxysmal tachycardia, can be referred to a lesion of the His hundle.

\title{
DMATATION OF THE HEART.'
}

\section{By Thosces A. Clittor, M.D.,}

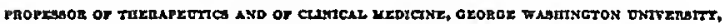

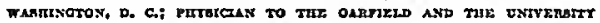
nosprtals, FAsmworos, b. c.

Ir Is not my intention to go into a detailed discussion of dilatation of the heart, but only to touch upon some of the more important points, more especially the etiology and treatment.

Dilatation of the heart is associnted with either a thickening or a thinging of its walls, more commonly the former, and may be looked upon as an index of the disproportion between the intracardiac pressure and the resisting power of those walls. One or all of the cavities may be affected.

Exrolocy. The majority of instances of cardinc dilatation may be said to result from one of the following factors, operating either singly or collectively: (1) An increase in the amount of work to be done by the heart, as in general arteriosclerosis, chronic nephritis, valvular disease, overstrain, etc; (2) an impairment of the power of the myocardium from degenerative changes, toxic conditions, etc.; and (3) failure of the cardiac muscular tone, as seen in some

1" Arch. f. kfin. Med, vol. lxwii.

1 Read at a meeting of the American Ciratological Associntion, Washington, D. C., 3Iny 7,8 , and $\theta, 1007$. 
instances of severe nervous shock, etc. Thus we see in arteriosclerosis and in chronic nephritis, hypertrophy and dilatation of the heart due to increased demands upon this organ. In valvular lesions of all varieties there is almost sure to occur more or less dilatation, usually with hypertrophy. Examples of overstrain are to be seen in athletes and in those whose occupations require great muscular effort. Oarsmen and long-distance runners necessarily tax their hearts to the utmost. The cardiac pulsations are greatly increased in force and in frequency to supply the increased demands of the muscular system and to accommodate the mpid return of the blood to the heart, but this may not be sufficient. Besides, the mechanical overfilling of the candinc chambers, which produces a severe strain on the contractility of the candiac muscle, there are also the fatigue products which probably have a toxic effect on the muscle fibers. With this combination at rork, there is small wonder that the heart gives way under the strain, and dilates in some instances. I am aware, horrever, that there are some observers who do not believe that a sound heart ever dilates from excessive muscular exertion alone.

Among the more important causes of myocardial degeneration are the acute infectious, disenses, such as diphtheria, influenza, and rheumatism, if we may class the latter as such. According to Iees? myocarditis is far more common in rheumatism than in diphtheria and influenza, but much less dangerous, and the microscope shows much less destruction of the musclc fibers. Not a few denths result from acute dilatation in diphtheria or shortly after apparent recovery, and many instances of weal heart finally presenting the picture of dilatation date back to an attack of epidemic influenza. A number of writers have called attention to dilatation in typhoid fever, notably Louis, Andral, Gunsburg, Wunderlich, and Stokes. The condition may be general or noted on either side of the heart. Romberg found considerable dilatation of the right ventricle and right auricle with a contracted and hard left heart. A typical example of cardiac dilatation in a case of typhoid fever came under my observation last fall, developing in the fifth or sixth week of the disease and rapidly cnding fatally.

In the more intense forms of anemia, cardiac dilatation is the rule, and probably accounts for many of the murmurs which we are wont to call hemic. Myocardial degeneration seen in those past middle life is most commonly due to failure of the blood supply of the cardiac muscle, resulting from sclerosis of the coronaries.

After considering the many definite and tangible causes of dilatation, such as myocandial degeneration, valvular lesions, nephritis, etc., there still remains a fairly large class in which we are not ablc

2 Brit. Med. Jour.. I001.

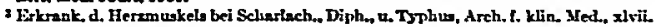


to find perfectly satisfactory explanntion. Here we must fall hack on the nervous system and say that the cause is loss of muscular tone; indeed, this seems not by any mean's an improbable solutionin fact it is urged by Colbeck that all forms of cardiac dilatation may he directly traced to loss of muscular tone. By muscular tone we menn that state of tension in which the muscles are beld - which is dependent on the nerve supply.

It is a well-known fact that severe shocks, joy, grief, or any severe nervous strain may cause a dilatation of the heart, and, as Broadhent has said, death may result actually from a broken heart. Immediate death under such circumstances, bowever, is prabobly due to cardiac inhibition. I am inclined to believe that small doses of opium, whicb often seem to act so satisfactorily in dilatation, produce results largely through the soothing effect upon the nervous system. Cheimisse $^{3}$ states that Marmorstein reported two instances of cardiac dilatation from shock during the rioting in Odessa. The patients were neurotic, and the sight of murder and pillage was the immediate cause. Many such examples are to be found in literature.

It is quite conceivable that under prolonged severe exertion even the pcrfectly normal heart might, and we know does, become exlausted and loses temporarily its muscular tone. In the majority of instances this form of dilatation is rather quickly recovered from, but not always. It is a wcll-known fact that the training which an atblete goes through for a strenuous competition is to give the muscles, and the heart muscle in particular, a chance to hypertrophy. The young, from their mode of life, are always more or less in training; hence the violent strains which their hearts are called upon to bear, do no specific harm, except, I helieve, in rare instances; but it is a vastly different matter when a man past forty, wbo has given up active exercise for some years, is called upon for some violent cffort, such as a sprint of a couple of squares to catch a car, or who, because of a too inscible temper, becomes involved in a bodily conflict. If this happens to one wbose heart is under the influence of nicotine or some such toxic agent, or who has a pre-existing heart trouble, such as a valvular lesion or a myocardial degeneration, dilatation of a serious nature may quickly develop witb all the usual indications.

The exciting cause may be any unusual muscular or mental effort. I recently saw a prominent lawyer who, though well advanced in years, had always been a man of remarkahle vigor, who hrought on the symptoms of dilatation ${ }^{-1}$ by the preparation of a long and important brief. He had just concluded his arduous task wben he was suddenly seized with dyspncen and oppression in the cardiac region. I found the heart considerably enlarged, acting very irregularly, 
and a mitral systotie murmur present. Whether this murmur was due to a true valvular lesion or to a relative insufficiency from dilatation I am unable to say, as he left for his home in the West as soon as he had partially recovered.

Another gentleman, whom I had the opportunity to observe for a number of years, suffered a severe dilatation from over-fatigue of body and mind during an active political campaign, and a second very acute attack, which nearly cost him his life, was the immediate result of rather vigorous abdominal massage. In this case there had been for many jears completely compensated mitral and aortie insuffieieneies, with but little enlargement of the heart.

Again, the symptoms of dilatation may be brought on by an acute illness in those who, though the subjects of ralrular lesions or some other disorder of the lieart, have acquired perfect compensation. I land such an instance under observation while writing this paper. A woman aged forty years, who has for a long time shown the physical signs of a mitral stcnosis, developed a bronchopneumonia, with a vcry harassing cough. After a few days of constant coughing, marked orthopnoea, with cedema of the lungs, developed. Examination of the heart showed a loud systolic murmur in the tricuspid aren, in addition to the pre-existing mitral stenotic bruit. Caffeine in liberal doses gave fairly prompt relief, and the wall of the right ventricle so far regained its tone that the systolic murmur was scarcely audible at the last examination.

One of the more recent instances which has come undor my observation was in the case of an old ! dy who suffered from a inyocardial degencration. One night she got out of bed, slipped on thic floor, and, in a riolent struggle to regain her feet before anyone slould find her up alone, hrought on a marked dilatation, from which she almost died. It is useless to multiply examples of this well-known condition.

Srarrosis. Sleeplessness is not infrequently the first symptom to attract the attention of the patient. Sometimes it is referred to the riolence of the heart's action or to an uncomfortable feeling of nervousness, or to a cough, evidently due to faulty circulation. In other instances there is aetual dyspnoea or eren orthopnoen. It is a strange faet that these sufierers often rest quietly for somc hours after retiring, only to he awakened in the early morning hy one of the alove-mentioned symptoms.

The possibility of cardiac insufficiency should al ways be borne in mind when insommia develops. A stimulant in such instances is often the best hypnotic. I well remember one patient in whom a small dose of digitalis produced such promipt sleep that it was mistaken for an opiate. There is usually complaint of weight and oppression over the precondium-seldom aetual pain. Sometimes the dilatation seems to make itself actually felt, the patient saying that lic feels as though the heart were too big for the chest. 
The pulse is usually rapid and, not uncommonly, arrlyythmic. Dyspncea at first oaly on exertioa, later becomes more or less coastant. Cyanosis and cedema of the ungs may develop, the latter beiag oae of the earliest aad most persisteat symptoms, as evidenced by cough with seromucous expectoration, which may he slightly pinkish or quite bloody, depending on the amount of congestion. In acute dilataton cedema of the lungs is one of the most urgent symptoms and not infrequently appears to be the immediate cause of death. Geaeral cedema is usually of later development, when there is ao longer any doubt as to the diagnosis. Many of those whose hearts are undergoing gradual dilatation suffer chiefly from gastro-intestinal disorders-flatulent dyspepsia or nausea, due to coagestion of the ahdominal organs; and it is often difficult to convince them that the heart is the cause of their trouble. The liver becomes congested and of ten greatly enlarged and painful to pressure, even if there be no complaint of heaviness in the right hypochoadrium. Congestion of the kidneys results ia scanty, more or less alhuminous urine, ia which casts are usually to he found.

Diagnosis. The diagnosis is based upon the preseace of the above-named symptoms and upon the followiag physical signs: The whole precordium may seem to throb with each systole of the ventricles, whea there is an associated hypertrophy of much nuagnitude; while in instances of dilatation with thinaing of the walls thcre may be ao visible impulse whatever, or oaly the merest undulatory wave in the neighborhood of the apex. The jugular veins may be distended and may pulsate. If the right ventricle is dilated, the epigastrium may pulsate. The apex heat is nearly always displaced to the left, and downward if the left veatricle is involved. By laying the ulnar surface of the hand parallel to and to the right of the sternum, a fair idea of the extension of the heart to the right may be ohtained hy the impulse which is often palpable to this sensitive part of the hand, although oae is likely to get a slightly exaggerated impression of the size of the heart hy this method. IIy attention was first called to this valuable point by C. H. Hoover. In percussion of the heart, I wish to lay great stress upon the advantage of the palpatory method over all others; its accuracy is often very gratifying. The cardiac dulness will be found to be iacreased to a greater or less degree, depending on the dilatation. An accurate determination of the area of dulness is of the greatest importance, and at the same time requires more skill and practice than any other part of the examination. There may or may not be heard eadocardial murmurs, due to true lesions of the valves, hut there is likely to be present the systolic murmur of a relative insufficieacy of the mitral or of the tricuspid valve or of both. Time alone will prove this point. The disappearnee of the murmur of a relative insufficiency is always encouraging, as it is an indication that the cardinc chambers are returning to the aormal sizc. 
(3. The splygmomanometer has been rather a disappointment as an aid to diagnosis in disenses of the heart. It is of value, however, in giving warning of possible danger ahead. For instance, the discovery of an abnormally high blood pressure at once suggests the presence of conditions, such as arteriosclerosis or chronic nephritis, which will sooner or later be likely to produce hypertrophy with dilatntion, and we are able to direct the life of the patient accordingly. The use of this exact method of estimnting the pressure also makes one much more accurate in the examination of the superficial artcries in determining the real force of the pulse. A point which was at first a surprise to me was the high blood pressure so frequently observed in spite of the very evident symptoms of cardiac insufficiency. I mean especinlly in the first few days of what might be called an acute dilatation, when there was dyspnoia, cedema of the lungs, arrhythmin of the pulse and other indications of circulatory insufficiency. As the condition improved the pressurc fell, and the reduction occurred in spite of the constant administration of digitalis and cardiac stimulants other than the nitrites. These observations were upon cases of dilatation with bypertroply. The elevation of pressure under such circumstances would appear to be due to exaggerated efforts of the heart and vessels to reestrblish the circulatory equilibrium.

Differential Dingxosis. The tro conditions with which dilatation might be confounded are simple hypertrophy and pericardial effusion. The former requires but little consideration as the symptoms are not the same, unless the walls of the heart harc begun to relax, nhen it falls into the class now under discussion. A pericandial effusion, howerer, is by no means so ensily differentiated from dilatation, as the symptoms may be practically the samc. In the former the cardiac impulse is generally less distinct, the first and second sounds weaker, and most important of all-there may be heard a pericardial friction rub, even though there exists a large effusion. It must be borne in mind, however, that the two conditions may co-exist. In effusion the area of dulness is of the classical irregular dome-shape, the apex being upward, and extends lower down, depressing the left lobe of the liver in some instances. The relation of the extent of dulness to the position of the apex beat, when it can be felt, is of importance. In cffusion the dulness extends to the left and below the position of the apex beat. Dulness in the right fifth interspace, as pointed out by Rotch, is a valuablc sign of effusion, as is also the broadening of the area of dulness toward the base of the dome when the patient assumes the sitting posture. If there still be doubt, the question may be quickly settled by the use of the fluoroscope, when the apparatus is avrilable; thc dilated heart will be seen to pulsate while the effusion will remain stationary. 
Trentuent. In an endeavor to relieve this conditon it is necessary to bear in mind the two cardinal objects: To lessen the amount of work which is required of the beart, and to increase the power of the beart to do its work. The first may be accomplisbed by absolute bodily and mental rest, by a ligbt diet, by active purgation, by relaxing the peripberal vessels, and by bleeding. Tbe second may be accomplisbed by the administration of cardiac stimulants, by baths, by judicious exercises, etc.

Propbylaxis is worth much in cases of beginning dilatation. If these patients can be got under control when the first indications manifest ihemselves, many attacks may be warded off by advice as to overstrain, either mental or physical. If men with large interests and women with excessive bousehold or social cares can be induced to ligbten their loads of responsibility; if beavy eaters can have their appetites controlled, much may be accomplisbed without recourse to medicine.

Even after sexious symptoms have actually developed, much may he done. without cardiac stimulants. Some of our patients yield promptly to rest in bed, a dose of calomel or blue mass, followed by salines. If this fails to restore the circulatory equilibrium, digitalis is turned to by the vast majority, and $I$, too, usually give it the prefcrence; but caffeine is, in my opinion, a very close second and not infrequently is superior. I think that I have noted this superiority especially in cases of tigb blood pressure, which would be ensily explained by the difference in pbysiological action of the tiro drugs. But at this point I want to cmphrsize the fact that digitalis in some cases is indispensable, in spite of high blood pressure, in spite of the most marked calcareous degeneration of the arteries, as far as they can be felt. In some instances our best efforts along these lines will fail, and the symptoms even grow worse-cyanosis and dyspncea increase, nausea develop with extreme restlessness, and the beart's action become more irregular and rapid. These are the cases wbicb require more beroic handling, and these are the cases, if properly selected, which are often benefited by bleeding. The patients wbo are best adapied to blood-letting are the pletboricmore usually men who, thougb suffering from some beart lesion, have, througb careful dietetic and bygienic regimen, been made to increase in weigbt and strength, and wbo, by some indiscretion, bave been smitten in the midst of comparative bealth.

Some prefer wet cups or leeches, and .bey may be very beneficial. Incidentally, I might say that I cannot see why their application over the precordium, in preference to any other area, should be of especial advantage, unless they sbould also act as counterirritants. My own experience has been with venesection; bence, I prefer the very simple method of opening a vein in the forearm and drawing off from 8 to 16 ounces of blood. The results are in some instances inost gratifying. I have seen the cyanosis improve at once, the 
nausea disappear while the blood was still flowing, and the patient express himself as much more comfortable. 'T'lis method of relieving the over-distended heart appeals to me as being one of the most mtional at our command, and get it is surprising how few ever resort to it. By unlonding the renous circulation, the overfilled leart is enabled more completely to empty itself, and the overstretched muscle fibers are once more allowed an opportunity to contract to somewhere their normal dimensions. After bleeding, cardiac tonics produce results which previously scemed unattain-
ablc.

I shall not mention the names of the army of drugs which have been used in dilatation of the heart, but will content myself with the mention of one more, which, if properly given, will be found most useful-that is opium. These patients are often possessed with that spirit of unrest, that condition of geneml wretchedness which it is hand to describe, but which is perfectly familiar to us all. For this symptom-complex there is nothing so useful as small doses of morphine. I have found as little as $\frac{1}{32}$ grain every four hours most beneficial; not only does it quiet the nervous system, but it seems to stimulate the heart, and in most instances appenrs to do no harm. I shall not take up the treatment of dilatation by exercises and baths. A discussion such as the present would hardly be complete without some mention of the most acute forms of dilatation. In these the anxious, terror-stricken expression, livid skin, threndy pulse, with cold nnd clammy sweat, indicates that death is imminent. The free use of nitroglycerin has, in some instances, seemed to be lifesaving, and I have rather !enrned to rely upon it under such circumstances. Caffeine is especially useful when cedema of the lungs is pronounced. In fact nitroglycerin, caffeinc, and digitalis may be given at the same time, as their promptness of action is about in the order named, so that the effect of the first two will have cntirely disappeared before the third makes itself felt. Nitroglycerin should, in my opinion, be reserved for emergencies such as the above and for the attacks of great oppression which are likely to come on from time to time in the less acute cases of dilatation. Its continued use is depressing. I have not mentioned strychninc because I have mather lost faith in it, having observed better effects from other remedies:

Diet. Upon this point there are two widely different opinions. The one, that only liquids should be given; the other, that a dry cliet is preferable, on the ground that the more liquid is taken into the system the more will be taken up by the vessels, and consequently the greater amount of fluid will have to be moved by the already overhden heart. After trying both methods, I have concluded that the dry diet is to be preferred, unless there arc decider uremic symptoms to be considered. Especially is this true when there is, as is so often the case, a tendency to tympanites. 